Negative results

\title{
RIC3 variants are not associated with Parkinson's disease in French-Canadians and French
}

\author{
Jay P. Ross ${ }^{\mathrm{a}, \mathrm{b}}$, Nicolas Dupré ${ }^{\mathrm{c}}$, Yves Dauvilliers ${ }^{\mathrm{d}}$, Stephanie Strong ${ }^{\mathrm{b}, \mathrm{e}}$, \\ Alexandre Dionne-Laporte ${ }^{\mathrm{b}, \mathrm{e}}$, Patrick A. Dion ${ }^{\mathrm{b}, \mathrm{e}}$, Guy A. Rouleau ${ }^{\mathrm{a}, \mathrm{b}, \mathrm{e}}, \mathrm{Z}^{\mathrm{Z}}$ Ziv Gan-Or ${ }^{\mathrm{b}, \mathrm{e}, *}$ \\ a Department of Human Genetics, McGill University, Montréal, Québec, Canada \\ ${ }^{\mathrm{b}}$ Department of Neurology and Neurosurgery, Montreal Neurological Institute, McGill University, Montréal, Québec, Canada \\ ${ }^{\mathrm{c}}$ Division of Neurology, CHU de Québec, Faculty of Medicine, Laval University, Quebec City, Québec, Canada \\ d Sleep Unit, National Reference Network for Narcolepsy, Department of Neurology, Hôpital-Gui-de Chauliac, CHU Montpellier, INSERM U1061, \\ Montpellier, France \\ ${ }^{\mathrm{e}}$ Department of Neurology and Neurosurgery, McGill University, Montréal, Québec, Canada
}

\section{A R T I C L E I N F O}

\section{Article history:}

Received 3 November 2016

Received in revised form 28 December 2016

Accepted 3 January 2017

Available online 11 January 2017

\section{Keywords:}

RIC3

Parkinson's disease

Genetics

\begin{abstract}
A B S T R A C T
Variants in the RIC3 gene have recently been suggested as a novel cause of Parkinson's disease (PD). Herein, the entire RIC3 gene was sequenced in a French-Canadian and French sample series of 535 PD patients and 527 unaffected controls. The effect of single variants and the combined effect of variants were calculated. Sequence Kernel association tests (SKAT, SKAT-O) were done on the entire gene level, and on the different domains and exons of RIC3. A total of 28 common and rare variants were identified in patients and controls. No significant association was found between any variant and haplotype in RIC3 and PD, and there was no over-representation of RIC3 variants at the entire gene, domain, or exon levels in patients versus controls. Our results do not support a role for RIC 3 mutations as a common cause of PD in the French-Canadian and French populations.
\end{abstract}

(c) 2017 Elsevier Inc. All rights reserved.

\section{Introduction}

Recently, a whole exome sequencing study was performed on a large family of Indian origin with autosomal dominant PD. The family included 10 affected individuals from 3 generations, and the whole exome sequencing suggested that a mutation in RIC3 (p.P57T) may be the cause of PD in this family (Sudhaman et al., 2016). An additional mutation, p.V168L, was identified in a single patient with young onset PD. RIC3 encodes the RIC3 (resistant to inhibitor of cholinesterase 3) -acetylcholine receptor chaperone, which promotes the proper folding and assembly of neuronal nicotinic acetylcholine receptors (nAChRs; Millar, 2008). In the present study, we sequenced the entire coding sequence and exon-intron boundaries of RIC3 to examine whether variants in this gene are associated with PD in French-Canadian and French patients and controls. See Supplementary Material for detailed introduction, methods, results, discussion, acknowledgements, and full reference list.

\footnotetext{
* Corresponding author at: Montreal Neurological Institute and Hospital, The Department of Neurology \& Neurosurgery, McGill University, 1033 Pine Avenue West, Ludmer Pavilion, Room 327, Montreal, Québec H3A 1A1, Canada. Tel.: +1-514398-6821; fax: +1-514 398-8248.

E-mail address: ziv.gan-or@mail.mcgill.ca (Z. Gan-Or).
}

\section{Methods}

\subsection{Population}

The study population included 535 unrelated, consecutivelyrecruited PD patients from clinics in Québec, Canada, and Montpellier, France and 527 ethnically-matched controls. The average age of patients was $65.6 \pm 9.9$ years (data on age were not available for 14 patients, male to female ratio of 1.8). The control population was composed of 157 elderly controls (average age $65.4 \pm 7.2$ years) and 352 young controls (average age $37.7 \pm 7.7$ years). All participants provided informed consent, and the procedures were approved by the institutional review boards.

\subsection{Sequencing}

Sequencing was performed using primers previously described (Sudhaman et al., 2016) to amplify the entire coding regions and exon-intron boundaries of the RIC3 gene.

\subsection{Statistical analysis}

Binary logistic regression adjusted for age and sex was performed to examine the association between RIC3 variants and 
Table 1

RIC3 variants in 535 Parkinson's disease patients and 527 controls

\begin{tabular}{|c|c|c|c|c|c|c|c|c|c|}
\hline rs number & Amino acid & Freq. ExAC & Polyphen2 score & SIFT score & Patients, $\mathrm{n}=535(\mathrm{AF})$ & Controls, $\mathrm{n}=527,(\mathrm{AF})$ & $p$ value & OR & $95 \% \mathrm{CI}$ \\
\hline \multicolumn{10}{|l|}{ Common variants } \\
\hline rs10839976 & p.L118L & 0.2691 & NA & $\mathrm{N} / \mathrm{A}$ & $226(0.217)$ & $215(0.212)$ & 0.4165 & 1.112 & $0.8602-1.439$ \\
\hline rs55990541 & p.C130Y & 0.0738 & 0.041 & 1 & $51(0.048)$ & $46(0.045)$ & 0.5091 & 1.184 & $0.7175-1.953$ \\
\hline rs73411617 & p.P135S & 0.04066 & 0.005 & 0.45 & $33(0.032)$ & $40(0.039)$ & 0.2775 & 0.7446 & $0.4373-1.268$ \\
\hline rs79313028 & Intronic & 0.01281 & NA & NA & $2(0.002)$ & $3(0.003)$ & 0.5802 & 2.232 & $0.1298-38.39$ \\
\hline rs11826236 & p.D351N & 0.07947 & 0.846 & 0.38 & $47(0.044)$ & $43(0.042)$ & 0.3813 & 1.264 & $0.7483-2.134$ \\
\hline \multicolumn{10}{|l|}{ Rare variants } \\
\hline \multirow[t]{4}{*}{ rs6578936 } & Splicing & 0.00654 & NA & NA & 0 & $1(0.001)$ & & & \\
\hline & p.V6A & & 0.03 & 0.11 & $1(0.001)$ & 0 & & & \\
\hline & p.A10S & & 0.997 & 0.08 & 0 & $2(0.002)$ & & & \\
\hline & p.A12V & & 0 & 1 & $1(0.001)$ & 0 & & & \\
\hline \multirow[t]{3}{*}{ rs145965152 } & p.K25R & 0.0014 & 0.041 & 0.75 & $2(0.002)$ & $3(0.003)$ & 0.8149 & 0.7787 & $0.09592-6.322$ \\
\hline & p.P63L & & 0.001 & 0.08 & 0 & $1(0.001)$ & & & \\
\hline & p.S70T & & 0.449 & 0.31 & $1(0.001)$ & $1(0.001)$ & 0.8373 & 1.533 & $0.02596-90.56$ \\
\hline \multirow[t]{2}{*}{ rs149313414 } & p.A73A & 0.0005111 & NA & $\mathrm{N} / \mathrm{A}$ & 0 & $1(0.001)$ & & & \\
\hline & p.A86A & & NA & $\mathrm{N} / \mathrm{A}$ & $1(0.001)$ & 0 & & & \\
\hline rs144806410 & p.P101S & 0.002737 & 1 & 0 & $5(0.005)$ & $2(0.002)$ & 0.9605 & 0.9555 & $0.1575-5.796$ \\
\hline \multirow[t]{2}{*}{ rs80168649 } & p.G121A & 0.007348 & 1 & 0.17 & $3(0.003)$ & $3(0.003)$ & 0.5889 & 0.5656 & $0.07158-4.469$ \\
\hline & p.T138S & & 0.001 & 0.68 & $1(0.001)$ & 0 & & & \\
\hline rs111370836 & Intronic & 0.00771 & NA & NA & 0 & $2(0.002)$ & & & \\
\hline rs144870134 & p.R191Q & 0.001499 & 0.266 & 0.16 & 0 & $1(0.001)$ & & & \\
\hline rs139685245 & p.V196F & 0.002661 & 1 & 0.02 & $1(0.001)$ & 0 & & & \\
\hline \multirow[t]{2}{*}{ rs773259414 } & p.R205K & 0.00002471 & 0.034 & 0.83 & 0 & $1(0.001)$ & & & \\
\hline & p.P216S & & 0.707 & 0.28 & $1(0.001)$ & 0 & & & \\
\hline rs11041753 & Intronic & & NA & NA & $7(0.007)$ & $6(0.006)$ & 0.2586 & 0.5053 & $0.1546-1.652$ \\
\hline rs765540849 & Intronic & & NA & NA & 0 & $1(0.001)$ & & & \\
\hline \multirow[t]{2}{*}{ rs747142587 } & p.A257S & 0.000008238 & 0.997 & 0.17 & 0 & $1(0.001)$ & & & \\
\hline & p.S279R & & 0 & 0.48 & $1(0.001)$ & 0 & & & \\
\hline rs749020968 & p.P281L & 0.000008237 & 0.058 & 0.18 & $2(0.002)$ & 0 & & & \\
\hline rs116932252 & p.D311N & 0.003748 & 1 & 0 & $6(0.006)$ & $7(0.007)$ & 0.8239 & 0.854 & $0.2128-3.428$ \\
\hline
\end{tabular}

Key: AF, allele frequency; $\mathrm{CI}$, confidence interval; Freq. ExAC, frequency in the ExAC database; OR, odds ratio.

Deleteriousness threshold values: polyphen2-greater than 0.86 , SIFT-less than 0.05 .

disease status (PLINK 1.07). To further examine the potential combined effect of RIC3 variants on risk for PD, SKAT (Sequence Kernel association test) and SKAT-O (optimal SKAT) were performed using $R$. These analyses were performed on the entire gene, as well as on each domain and each exon of the gene, to examine whether accumulation of variants in specific domains or exons could be associated with PD.

\section{Results}

A total of 28 different variants in RIC3 were observed (Table 1). The RIC3 variants reported to cause PD, p.P57T, and p.V168L (Sudhaman et al., 2016) were not observed in our cohort. Binary logistic regression, with age and sex as covariates for adjustment, demonstrated that none of the variants were specifically associated with PD (Table 1). Logistic regression with age and sex as covariates was performed on the inferred haplotypes. Four commonly shared haplotypes were identified (Supplementary Table 1), none of which were associated with PD risk ( $p=0.3155-0.9968)$. RIC3 includes 3 domains (luminal, helical, and cytoplasmic) and 6 exons. There was no association between RIC3 variants at the gene level, domain levels, or exon levels analyzed using SKAT and SKAT-O (Table 2). In addition, there was no difference in frequencies of variants predicted to be damaging by either Polyphen2 (Adzhubei et al., 2010) or SIFT (Kumar et al., 2009; 62 [15.8\%] in patients, 58 [15.3\%] in controls, $p=0.64$, Table 2).

\section{Discussion}

Despite the well-segregating variant observed in the original family (Sudhaman et al., 2016), none of the variants identified in our French-Canadian and French cohort showed clear association with PD. One variant, p.P101S, was observed in more patients than controls, though at a nonsignificant $p$ value, probably due to random distribution difference. The present study cannot rule out a role for RIC3 in PD, since it is possible that disease causing variants in RIC3 occur only in specific populations, such as the South-Asian population of the original study. Similar examples had already been demonstrated in PD. An association with PD of mutations in SMPD1

Table 2

Sequence Kernel association test (SKAT) ${ }^{\mathrm{a}}$ analyses of RIC3 at the entire gene level, domain level, exon level, and function of variant level

\begin{tabular}{lcccc}
\hline Level of comparison & $\begin{array}{l}\text { Cases with } \\
\text { allele }\end{array}$ & $\begin{array}{l}\text { Controls with } \\
\text { allele }\end{array}$ & Marker (n) & $p$ Value \\
\hline Entire RIC3 Gene & 392 & 380 & 25 & 0.8405 \\
$\begin{array}{l}\text { Domains } \\
\text { Lumenal }\end{array}$ & 6 & 8 & 8 & 0.4575 \\
$\quad$ Helical & 1 & 0 & 1 & 0.5173 \\
$\quad$ Cytoplasmic & 372 & 357 & 13 & 0.7918 \\
Exons & & & & \\
$\quad$ Exon 1 & 4 & 5 & 4 & 0.4146 \\
$\quad$ Exon 2 & 7 & 5 & 5 & 0.5569 \\
$\quad$ Exon 3 & 314 & 304 & 5 & 1.000 \\
$\quad$ Exon 4 & 0 & 0 & 0 & NA \\
$\quad$ Exon 5 & 2 & 2 & 3 & 0.6162 \\
$\quad$ Exon 6 & 56 & 51 & 5 & 0.4462 \\
$\quad$ Intronic & 9 & 13 & 3 & 0.5315 \\
Type of mutation & & & & \\
$\quad$ Nonsynonymous/Splicing & 155 & 151 & 20 & 0.8157 \\
$\quad$ Synonymous & 237 & 229 & 5 & 0.5964 \\
Functional prediction & & & & \\
$\quad$ Damaging & 62 & 58 & 7 & 0.6415 \\
$\quad$ Tolerated & 330 & 322 & 18 & 0.8630 \\
\hline
\end{tabular}

a SKAT-O was also performed with very similar results (data not shown). 
was reported in the Ashkenazi-Jewish population (Gan-Or et al., 2013), which was replicated in an independent study of an additional Ashkenazi-Jewish population, but only few other studies confirmed this association in other populations. It is therefore possible that specific gene variants which may lead to PD can be restricted to specific populations. Furthermore, it is possible that RIC3 mutations lead to young or early onset PD, hence cohorts of young or early onset PD should be further investigated.

Overall, our results suggest that RIC3 mutations are not a common cause of PD in French-Canadian and French patients, and that further study will be required to examine these hypotheses and to determine the relationship between RIC3, PD, and function of the cholinergic system.

\section{Disclosure statement}

The authors have no actual or potential conflicts of interest. Acknowledgements

This study is funded by Michael J. Fox Foundation for Parkinson's Research.

\section{Appendix A. Supplementary data}

Supplementary data associated with this article can be found, in the online version, at http://dx.doi.org/10.1016/j.neurobiolaging. 2017.01.005.

\section{References}

Adzhubei, I.A., Schmidt, S., Peshkin, L., Ramensky, V.E., Gerasimova, A., Bork, P. Kondrashov, A.S., Sunyaev, S.R., 2010. A method and server for predicting damaging missense mutations. Nat. Methods 7, 248-249.

Gan-Or, Z., Ozelius, L.J., Bar-Shira, A., Saunders-Pullman, R., Mirelman, A. Kornreich, R., Gana-Weisz, M., Raymond, D., Rozenkrantz, L., Deik, A. Gurevich, T., Gross, S.J., Schreiber-Agus, N., Giladi, N., Bressman, S.B., OrrUrtreger, A., 2013. The p.L302P mutation in the lysosomal enzyme gene SMPD1 is a risk factor for Parkinson disease. Neurology 80, 1606-1610.

Kumar, P., Henikoff, S., Ng, P.C. 2009. Predicting the effects of coding nonsynonymous variants on protein function using the SIFT algorithm. Nat. Protoc. $4,1073-1081$.

Millar, N.S., 2008. RIC-3: a nicotinic acetylcholine receptor chaperone. Br. J. Pharmacol. 153 (Suppl 1), S177-S183.

Sudhaman, S., Muthane, U.B., Behari, M., Govindappa, S.T., Juyal, R.C., Thelma, B.K., 2016. Evidence of mutations in RIC3 acetylcholine receptor chaperone as novel cause of autosomal-dominant Parkinson's disease with non-motor phenotypes. J. Med. Genet. 53, 559-566. 